\title{
BMJ Open Long-term exposure to ambient ozone and mortality: a quantitative systematic review and meta-analysis of evidence from cohort studies
}

\author{
R W Atkinson, ${ }^{1}$ B K Butland, ${ }^{1}$ C Dimitroulopoulou, ${ }^{2}$ M R Heal, ${ }^{3} \mathrm{~J}$ R Stedman, ${ }^{4}$ \\ N Carslaw, ${ }^{5}$ D Jarvis, ${ }^{6}$ C Heaviside, ${ }^{2}$ S Vardoulakis, ${ }^{2}$ H Walton, ${ }^{7}$ H R Anderson ${ }^{1,7}$
}

To cite: Atkinson RW, Butland BK,

Dimitroulopoulou C, et al. Long-term exposure to ambient ozone and mortality: a quantitative systematic review and meta-analysis of evidence from cohort studies. BMJ Open 2016;6: 0009493. doi:10.1136/bmjopen-2015009493

- Prepublication history and additional material is available. To view please visit the journal (http://dx.doi.org/ 10.1136/bmjopen-2015009493).

Received 23 July 2015 Revised 9 December 2015 Accepted 10 December 2015

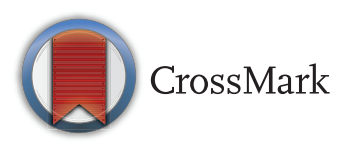

For numbered affiliations see end of article.

Correspondence to Dr RW Atkinson; atkinson@sgul.ac.uk

\section{ABSTRACT}

Objectives: While there is good evidence for associations between short-term exposure to ozone and a range of adverse health outcomes, the evidence from narrative reviews for long-term exposure is suggestive of associations with respiratory mortality only. We conducted a systematic, quantitative evaluation of the evidence from cohort studies, reporting associations between long-term exposure to ozone and mortality.

Methods: Cohort studies published in peer-reviewed journals indexed in EMBASE and MEDLINE to September 2015 and PubMed to October 2015 and cited in reviews/key publications were identified via search strings using terms relating to study design, pollutant and health outcome. Study details and estimate information were extracted and used to calculate standardised effect estimates expressed as HRs per $10 \mathrm{ppb}$ increment in long-term ozone concentrations.

Results: 14 publications from 8 cohorts presented results for ozone and all-cause and cause-specific mortality. We found no evidence of associations between long-term annual $\mathrm{O}_{3}$ concentrations and the risk of death from all causes, cardiovascular or respiratory diseases, or lung cancer. 4 cohorts assessed ozone concentrations measured during the warm season. Summary HRs for cardiovascular and respiratory causes of death derived from 3 cohorts were $1.01(95 \% \mathrm{Cl} 1.00$ to 1.02$)$ and $1.03(95 \% \mathrm{Cl}$ 1.01 to 1.05$)$ per $10 \mathrm{ppb}$, respectively.

Conclusions: Our quantitative review revealed a paucity of independent studies regarding the associations between long-term exposure to ozone and mortality. The potential impact of climate change and increasing anthropogenic emissions of ozone

precursors on ozone levels worldwide suggests further studies of the long-term effects of exposure to high ozone levels are warranted.

\section{INTRODUCTION}

Outdoor air pollution comprises a mixture of particles and gases and has been associated with a range of acute and chronic health

\section{Strengths and limitations of this study}

- This is the first quantitative review and meta-analysis of cohort evidence for long-term exposure to ozone and a range of causes of death.

- Fourteen publications from eight cohorts were identified. The majority of cohorts were from the USA and most of these focused on selected population subgroups.

- We found no evidence of associations between long-term annual $\mathrm{O}_{3}$ concentrations and the risk of death. Studies that used $\mathrm{O}_{3}$ concentrations measured during the warmer months as the exposure metric generally reported positive associations, especially with respiratory mortality.

- Climate change and increasing anthropogenic emissions of ozone precursors on ozone levels worldwide is likely to increase the population exposure to ozone. For the impact of these changes on mortality to be estimated further, cohort studies in representative populations utilising comparable ozone metrics are required.

effects. ${ }^{1}$ An important component of this mixture of pollutants is ozone $\left(\mathrm{O}_{3}\right)$, a gaseous pollutant formed by atmospheric chemical reactions involving nitrogen oxides $\left(\mathrm{NO}_{\mathrm{x}}\right)$ and volatile organic compound precursor gas emissions, and driven by solar radiation and temperature. $^{23}$ Ozone is a highly reactive, oxidative gas and the concentrations of $\mathrm{O}_{3}$ at a given time and place are also determined by the rate of loss through chemical reactions, the rate of surface deposition and long-range atmospheric transport processes which can vary with season and meteorological conditions. Climate change, as well as changes in anthropogenic emissions of $\mathrm{O}_{3}$ precursors, is likely to have an effect on ground-level $\mathrm{O}_{3}$ concentrations in the future. ${ }^{45}$

The highly reactive nature of $\mathrm{O}_{3}$ initiates oxidative stress when it enters the 
respiratory tract. ${ }^{2}$ Epidemiological studies have demonstrated adverse associations between short-term exposure to $\mathrm{O}_{3}$ and human health including reduced respiratory function and increased hospital admissions and deaths from respiratory diseases. ${ }^{1}{ }^{2}$ Associations between short-term exposure to $\mathrm{O}_{3}$ and cardiovascular mortality have also been reported; however, associations with cardiovascular morbidity are less convincing. ${ }^{6}$

In contrast to the evidence from short-term exposure studies, the evidence for adverse health effects associated with long-term exposure to $\mathrm{O}_{3}$, that is, average exposure measured over years, is mixed. The 2005 global update to the WHO air quality guidelines ${ }^{7}$ did not find support for an association with mortality. In their update of the 2006 Air Quality Criteria Document, ${ }^{8}$ the US Environmental Protection Agency (EPA) concluded that there was evidence suggestive of an association with respiratory mortality but limited support for an association with total and cardiopulmonary mortality, ${ }^{6}$ a view endorsed by the comprehensive review of the evidence in support of the revision of the European Union's (EU) air quality policies. ${ }^{1}$ While both of these reviews covered a wide range of possible health effects, both excluded recent large cohort studies in the $\mathrm{UK}^{9}$ and the USA. ${ }^{10}$ Furthermore, both reviews presented a narrative assessment of the evidence and did not attempt a quantitative evaluation of hazard or meta-analysis.

There is an important need to develop better concentration response functions that can be used in health impact assessments such as the Global Burden of Disease $^{11}$ and for modelling the potential ozone impacts associated with climate change. In this review, we present a quantitative evaluation of the evidence from cohort studies published in the peer-reviewed literature to October 2015, reporting associations between longterm exposure to ozone and mortality. We also assess the evidence stratified by cause of death, during the 'warm season' and after adjustment for fine particle concentrations.

\section{MATERIALS AND METHODS}

\section{Systematic ascertainment of cohort studies}

Cohort studies published in peer-reviewed journals were identified from searches of EMBASE (between 1974 and week 40 2015) and MEDLINE (1946 to September week 4 2015) within Ovid. Three search strings, relating to study design, health outcome and pollutant were used without language restriction (provided in the online supplementary material). Studies identified in each search were combined and duplicates (241) removed within Ovid.

A screening process to identify cohort studies assessing associations between long-term exposure to ozone and mortality was applied to the remaining 277 records. This process used the study title and abstract to identify potential studies for which the full paper was downloaded and checked. Exclusion criteria related to: (1) article type, (2) study design, (3) outcome, (4) exposure, and (5) use of individual rather than ecological covariates and further details of these criteria are provided in the online supplementary material. A total of 253 records were deleted. The main reasons for removal were: conference abstracts/notes, reviews, not cohort design and no ozone data in study. The literature searching and screening was undertaken by BKB.

We also conducted a separate search of PubMed (6 October 2015), undertaken by RWA and using three similar search terms (provided in the online supplementary material). Studies identified in each PubMed search were downloaded to Reference Manager databases (2014 Thomson Reuters) which were then combined and duplicates identified and removed. Two publications, additional to those returned in the Ovid searches, were identified. One study was published subsequent to the Ovid search date ${ }^{12}$ and the second was a reanalysis of an existing cohort with a focus on particulate matter. ${ }^{13}$ Finally, we included three known potentially relevant early publications. ${ }^{14-16}$ In total, 29 cohort studies were available for detailed evaluation to determine their inclusion in our review.

Each study was then further assessed against inclusion/exclusion criteria relating to covariate adjustment and provision of quantitative data to facilitate standardisation of hazard ratio (HR). Details of these exclusion/ inclusion criteria are also given in the online supplementary material. Seven cohort studies did not include adjustment for key confounders (age, sex, body mass index, smoking and socioeconomic status) and were excluded. ${ }^{17-23}$ Five studies ${ }^{14}{ }^{16}{ }^{24-26}$ did not provide numerical values for HRs and associated 95\% CIs together with the necessary data to enable standardisation of the HR (to an increment of $10 \mathrm{ppb}$ ). We do, however, note the qualitative findings from these studies. One study of respiratory mortality ${ }^{27}$ included contributory respiratory causes of death as well as underlying causes and was not included in our quantitative assessment of the evidence because of this non-standard definition of cause of death. Finally, two studies 1328 duplicated data presented in other publications ${ }^{15} 29$ and were excluded. Hence, 14 studies met our inclusion/ exclusion criteria and were included in our quantitative review. $^{9} 10121526 \quad 29-37$ The process, together with the numbers of studies identified at each stage, is illustrated in figure $1 .^{38}$

\section{Data extraction and coding}

For each cohort study, the following details were extracted: (1) citation details (title, authors, date of publication, etc); (2) cohort details including study location (country/city), study population, follow-up period(s), confounder adjustment; (3) details of the effect estimates including diagnosis, unit of measurement, concentration range for HR, metric description (annual mean, etc), period of year for exposure assessment (either all-year or 'warm season' according to the 

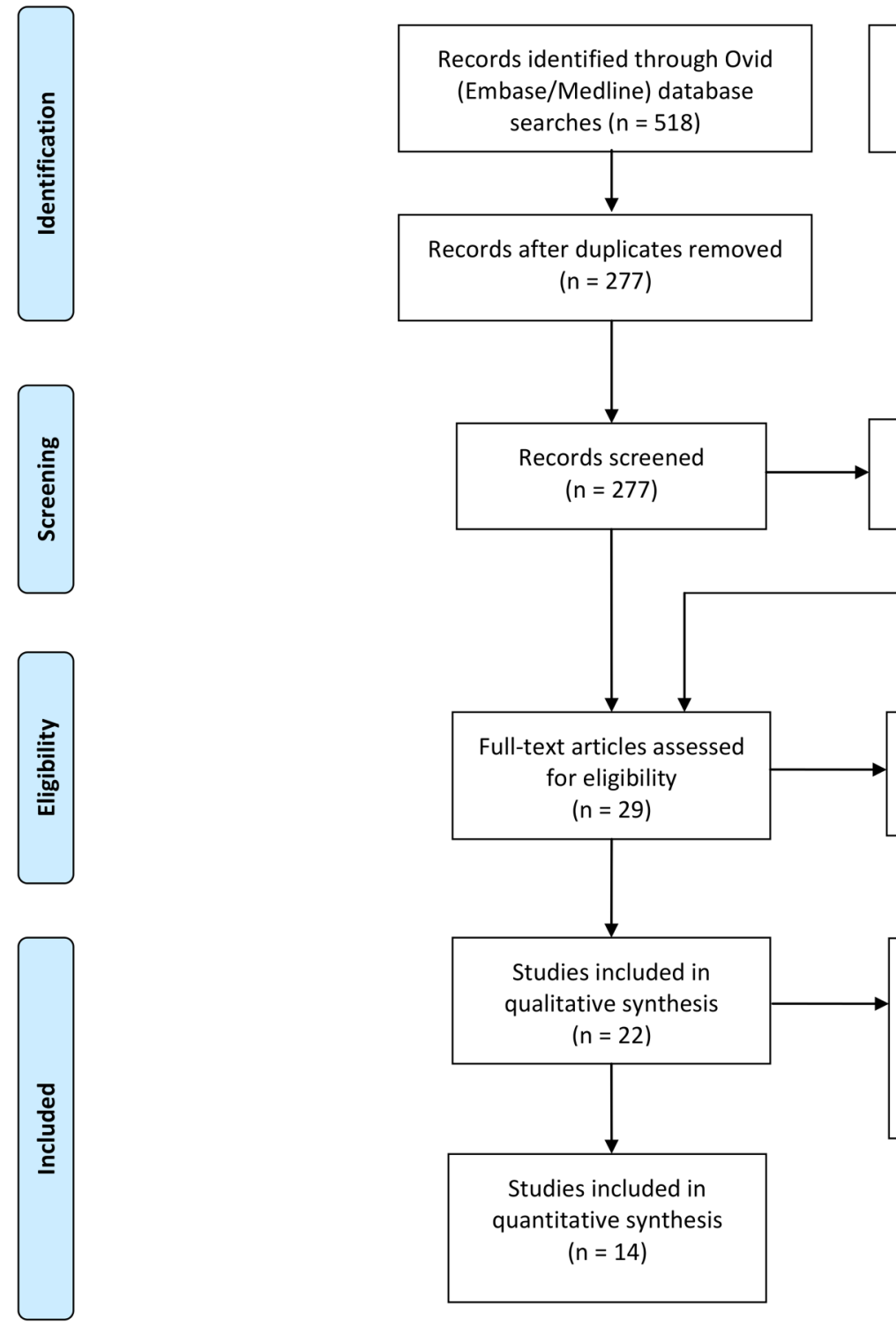

Additional records identified

(a) Pubmed $(n=2)$

(b) Citations/references $(n=3)$

Studies excluded

a) Confounder adj $(n=7)$

Studies excluded from

qualitative assessment

a) No standardised HR $(n=5)$

b) Non-standard outcome $(n=1)$

c) Replication ( $\mathrm{n}=2$ )

Figure 1 Overview of ascertainment of studies.

definition used in the original studies). These data were used to characterise/describe each cohort and to calculate standardised HRs and 95\% confidence interval (CI) expressed per $10 \mathrm{ppb}$ increase in $\mathrm{O}_{3}$ concentration. Where necessary, estimates reported in $\mu \mathrm{g} / \mathrm{m}^{3}$ were converted to ppb using $1 \mathrm{ppb}=2 \mu \mathrm{g} / \mathrm{m}^{3}$ at an ambient pressure of $1 \mathrm{~atm}$ and a temperature of $25^{\circ} \mathrm{C}$. This process was undertaken by BKB and checked by RWA.

The STATA program 'metan' was used to produce forest plots and to undertake random-effects meta-analysis where three or more estimates from separate cohorts were available for a specific cause of death. Where a cohort was analysed more than once, the estimate from the most recent study analysed, the largest sample size, most recent exposure and follow-up periods was selected for inclusion in the meta-analysis. This process ensured the size and direction the HRs reported in the studies did not influence their selection for meta-analysis, therefore limiting the potential for selection bias.

\section{RESULTS}

Our literature search identified 14 publications from eight cohorts reporting HRs for ozone and mortality and associated data to enable standardisation. Key characteristics of each study are summarised in the online supplementary material. Six cohorts focused on selected population subgroups: Seventh Day Adventists non-Hispanic white non-smokers (Adventist Health Study of Smog; AHSMOG), white participants (six cities), male veterans with diagnosed hypertension (Washington University - Electric Power Research Institute Veterans Cohort; WU-EPRI), and three selected occupation cohorts: female teachers (California Teachers Study; CTS), energy workers (Gazel) and Taiwanese civil servants. The American Cancer Society Cancer Prevention Study II (ACS CPS II) cohort was comprised of mainly friends, neighbours, acquaintances and relatives of volunteer recruiters. One study used administrative data to construct a primary care cohort (CPRD). The majority of 


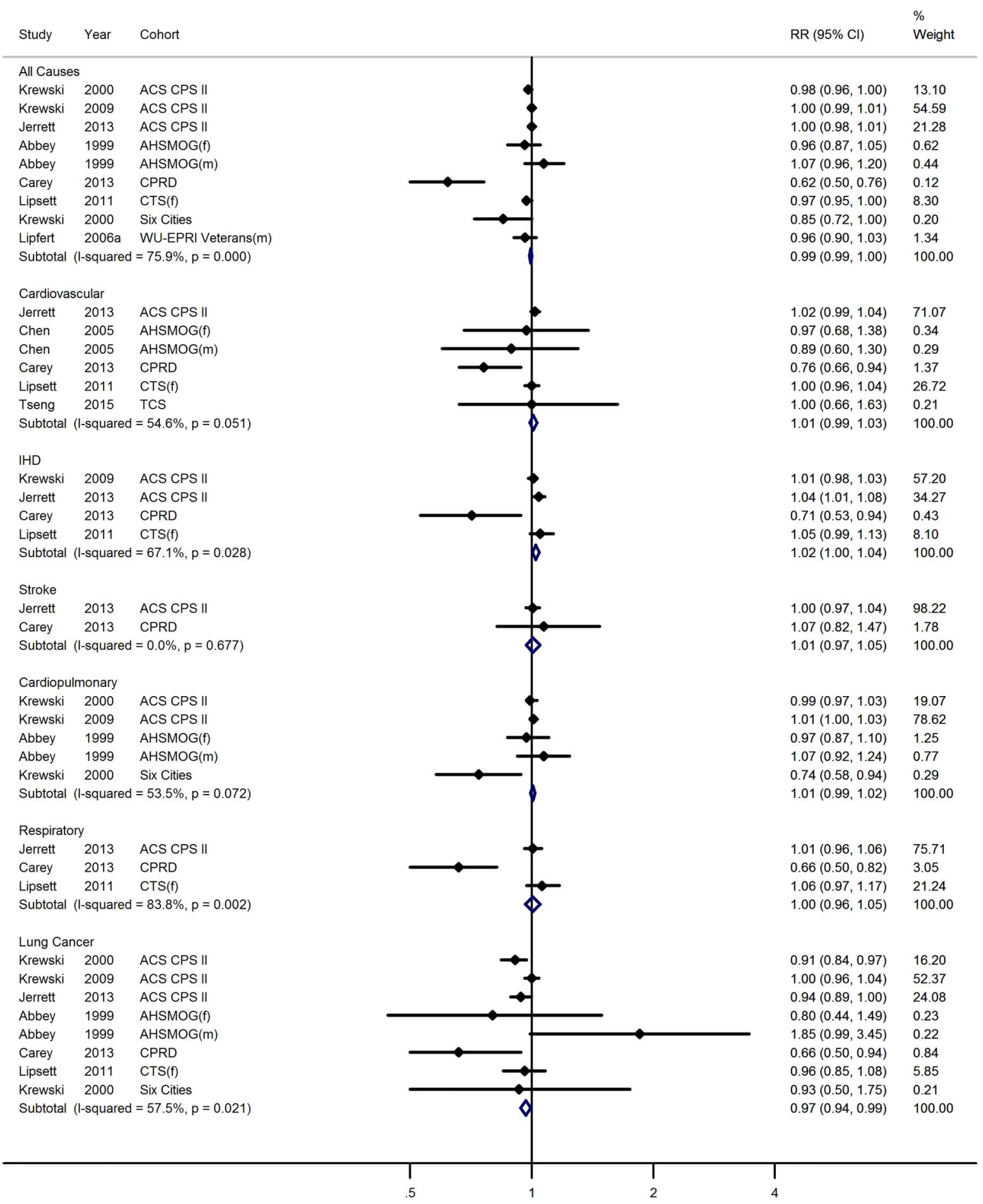

Figure 2 RR $(95 \% \mathrm{Cl})$ of death per $10 \mathrm{ppb}$ increase in long-term exposure to ozone. ACS CPS II, American Cancer Society Cancer Prevention Study II; AHSMOG, Adventist Health Study of Smog; CTS, California Teachers Study; IHD, ischaemic heart disease; RR, relative risk; WU-EPRI, Washington University - Electric Power Research Institute Veterans Cohort.

cohorts $(5 / 8)$ and publications $(11 / 14)$ were from the USA with the ACS CPS II cohort analysed in five separate publications. In total, 12/14 studies assessed associations with all-cause mortality and 11/14 cause-specific mortality. Summer or peak $\mathrm{O}_{3}$ measures were assessed in 8/14 studies, and 8/14 studies reported associations adjusted for mass of particles with a median aerodynamic diameter $<2.5 \mu \mathrm{m}\left(\mathrm{PM}_{2.5}\right)$.

\section{All season}

Standardised effect estimates, expressed as the HR $(95 \%$ CI) per $10 \mathrm{ppb}$ increase in $\mathrm{O}_{3}$, for all-cause and causespecific mortality are shown in the forest plot in figure 2 , and random-effects summary estimates are presented in table 1. We found no evidence of an association between long-term annual $\mathrm{O}_{3}$ concentrations and the risk of death from all causes. Meta-analysis of the seven 
Table 1 Meta-analytic summary estimates by cause of death

\begin{tabular}{|c|c|c|c|c|}
\hline Cause of death & Study citation & Number of estimates & HR (95\% Cl) & $I^{2}(\%)^{\star}$ \\
\hline \multicolumn{5}{|l|}{ All year } \\
\hline All causes & 91529303436 & $7 \dagger$ & $0.96(0.92$ to 1.00$)$ & 81 \\
\hline Cardiovascular & 9123236 & $5 \dagger$ & $0.98(0.93$ to 1.04$)$ & 55 \\
\hline Ischaemic heart disease & 92936 & 3 & $1.00(0.92$ to 1.09$)$ & 72 \\
\hline Cardiopulmonary & 152930 & $4 \dagger$ & $0.98(0.90$ to 1.07$)$ & 59 \\
\hline Respiratory & 91036 & 3 & $0.94(0.81$ to 1.10$)$ & 84 \\
\hline Lung cancer & 915293036 & $6 \dagger$ & 0.95 (0.83 to 1.08$)$ & 55 \\
\hline \multicolumn{5}{|l|}{ Warm season/peak ozone } \\
\hline All causes & 29343637 & 4 & 1.00 (0.99 to 1.02$)$ & 46 \\
\hline Cardiovascular & 263637 & 3 & 1.01 (1.00 to 1.02$)$ & 0 \\
\hline Respiratory & 263637 & 3 & $1.03(1.01$ to 1.05$)$ & 0 \\
\hline
\end{tabular}

HRs from the six cohorts gave a summary $\mathrm{HR}=0.96$ (95\% CI 0.92 to 1.00$)$ per $10 \mathrm{ppb}$ increase in $\mathrm{O}_{3}$ with evidence of heterogeneity $\left(\mathrm{I}^{2}=81 \%\right)$. Similarly, we did not find evidence for associations between long-term annual $\mathrm{O}_{3}$ concentrations and deaths from cardiovascular, ischaemic heart disease (IHD), cardiopulmonary and respiratory diseases and lung cancer (table 1 ).

\section{Warm season}

$\mathrm{O}_{3}$ concentrations during the 'warm season' (defined either as the period April to September or July to September or by selecting peak annual concentrations) were reported in the ACS CPS II, CTS, WU-EPRI and Gazel cohorts (figure 3). HRs for all-cause mortality were generally close to unity with $95 \%$ CI that encompassed unity. Associations for cardiopulmonary and respiratory causes of death were more convincing with HRs in the range 1.01-1.02 and 1.02-1.04, respectively, with lower confidence limits close to 1 other than for the French Gazel cohort. Summary HRs derived from meta-analysis of three or more cohorts (table 1) showed no association with all-cause mortality but positive associations with causespecific mortality, respiratory in particular. The reanalysis of the ACS CPS II cohort by Jerrett et $a l^{26}$ included almost 500000 participants across the USA and reported a HR for respiratory mortality of 1.03 (95\% CI 1.01 to 1.05$)$ per $10 \mathrm{ppb}$ increase in the average daily maximum $1 \mathrm{~h}$ ozone concentrations measured between April and September. They also considered the impact of adjusting for ambient temperature in 90 of the 96 metropolitan statistical areas and found no material difference in the $\mathrm{O}_{3} \mathrm{HR}$. Finally, the authors assessed the shape of the concentrationresponse function and found no evidence that a threshold model specification improved model fit when compared with a non-threshold linear model.

\section{Adjustment for $\mathrm{PM}_{2.5}$}

$\mathrm{O}_{3}$ concentrations and death from a range of diseases adjusted for concentrations of fine particles $\left(\mathrm{PM}_{2.5}\right)$ were studied in five cohorts (ACS CPS II, CTS, CPRD, WU-EPRI and Gazel) though the bulk of the evidence was from the ACS (figure 4). Results from these studies do not suggest a positive association between $\mathrm{O}_{3}$ and allcause or cause-specific mortality, other than the single estimate for respiratory mortality from the ACS CPS II cohort. $^{26}$

\section{Qualitative studies}

Four of the five studies that did not provide numerical data to enable the standardisation of the HR and CIs and hence inclusion in our quantitative review found no evidence of statistically significant associations with mortality. $^{14162539}$ The fifth study reported elevated significant overall associations with mortality. ${ }^{24}$

\section{DISCUSSION}

This quantitative systematic review of the evidence for an association between long-term exposure to $\mathrm{O}_{3}$ and an increased risk of death identified a small literature base dominated by US studies and the ACS CPS II cohort in particular. We found no evidence of associations between long-term annual $\mathrm{O}_{3}$ concentrations and the risk of death. Studies that used $\mathrm{O}_{3}$ concentrations measured during the warmer months or peak ozone $(95 \%$ centile of daily maximum $1 \mathrm{~h}$ ozone) as the exposure metric generally reported positive associations, especially with cardiopulmonary and respiratory mortality.

Previous reviews of the health effects of long-term exposure to $\mathrm{O}_{3}$ have provided narrative assessments of the cohort literature as part of comprehensive assessments of the epidemiological and toxicological evidence. ${ }^{16}$ Prueitt et al ${ }^{40}$ utilised the studies identified in the EPA review as a basis for a weight of evidence analysis for long-term exposure to $\mathrm{O}_{3}$ and cardiovascular disease. Cohort studies published since earlier reviews ${ }^{78}$ were examined and revisions to previous concluding statements considered. Our focus on a quantitative 


\begin{tabular}{|c|c|c|c|}
\hline Study & Cohort & Year & $\mathrm{RR}(95 \% \mathrm{Cl})$ \\
\hline \multicolumn{4}{|c|}{ All Causes } \\
\hline Bentayeb & GAZEL & 2015 & $0.96(0.81,1.14)$ \\
\hline Lipsett & $\operatorname{CTS}(\mathrm{f})$ & 2011 & $0.99(0.97,1.00)$ \\
\hline Jerrett & ACS CPS II & 2009 & $1.00(1.00,1.01)$ \\
\hline Krewski & ACS CPS II & 2009 & $1.01(1.00,1.02)$ \\
\hline Smith & ACS CPS II & 2009 & $1.01(1.00,1.02)$ \\
\hline Lipfert & WU-EPRI V & n2003 & $1.02(1.01,1.02)$ \\
\hline Lipfert & WU-EPRI V & $n 2006 b$ & $1.02(1.01,1.04)$ \\
\hline Lipfert & WU-EPRI V & m2006a & $1.03(0.99,1.07)$ \\
\hline \multicolumn{4}{|c|}{ Cardiovascular } \\
\hline Bentayeb & GAZEL & $2015 \leftarrow$ & $0.89(0.48,1.64)$ \\
\hline Lipsett & $\mathrm{CTS}(\mathrm{f})$ & 2011 & $1.01(0.98,1.03)$ \\
\hline Jerrett & ACS CPS II & 2009 & $1.01(1.00,1.02)$ \\
\hline \multicolumn{4}{|l|}{$\mathrm{IHD}$} \\
\hline Krewski & ACS CPS II & 2009 & $1.01(0.99,1.02)$ \\
\hline Jerrett & ACS CPS II & 2009 & $1.01(1.00,1.03)$ \\
\hline Lipsett & $\mathrm{CTS}(\mathrm{f})$ & 2011 & $1.04(1.00,1.08)$ \\
\hline \multicolumn{4}{|c|}{ Cardiopulmonary } \\
\hline Jerrett & ACS CPS II & 2009 & $1.01(1.01,1.02)$ \\
\hline Krewski & ACS CPS II & 2009 & $1.02(1.00,1.03)$ \\
\hline Smith & ACS CPS II & 2009 & $1.02(1.01,1.04)$ \\
\hline \multicolumn{4}{|c|}{ Respiratory } \\
\hline Bentayeb & GAZEL & 2015 & $1.02(0.66,1.58)$ \\
\hline Jerrett & ACS CPS ॥ & 2009 & $1.03(1.01,1.05)$ \\
\hline Lipsett & $\mathrm{CTS}(\mathrm{f})$ & 2011 & $1.04(0.99,1.09)$ \\
\hline \multicolumn{4}{|c|}{ Lung Cancer } \\
\hline Lipsett & CTS(f) & 2011 & $0.98(0.92,1.04)$ \\
\hline Krewski & ACS CPS II & 2009 & $0.99(0.96,1.02)$ \\
\hline
\end{tabular}

Figure $3 \mathrm{RR}(95 \% \mathrm{Cl})$ of death per $10 \mathrm{ppb}$ increase in long-term 'warm-season' ozone exposure. ACS CPS II, American Cancer Society Cancer Prevention Study II; IHD, ischaemic heart disease; RR, relative risk; WU-EPRI, Washington University Electric Power Research Institute Veterans Cohort.

analysis of all cohorts, irrespective of publication date, complements the narrative approach by: (1) facilitating an assessment of the number of cohorts, the number of published analyses and reanalyses as well as basic information such as participant characteristics and exposure estimation methods; (2) providing a graphical summary of all of the evidence (in the form of a forest plot) to enable a broad overview of the direction, magnitude and precision of all study findings; and (3) providing, where possible, summary HRs for use in health impact assessment exercises. Concentration response functions from cohort studies have been used previously in burden and impact calculations. ${ }^{1141}$ A disadvantage of our quantitative approach is that it does not reflect the diversity between studies in the methods for estimating exposure to $\mathrm{O}_{3}$, the definition of potential confounders and the 


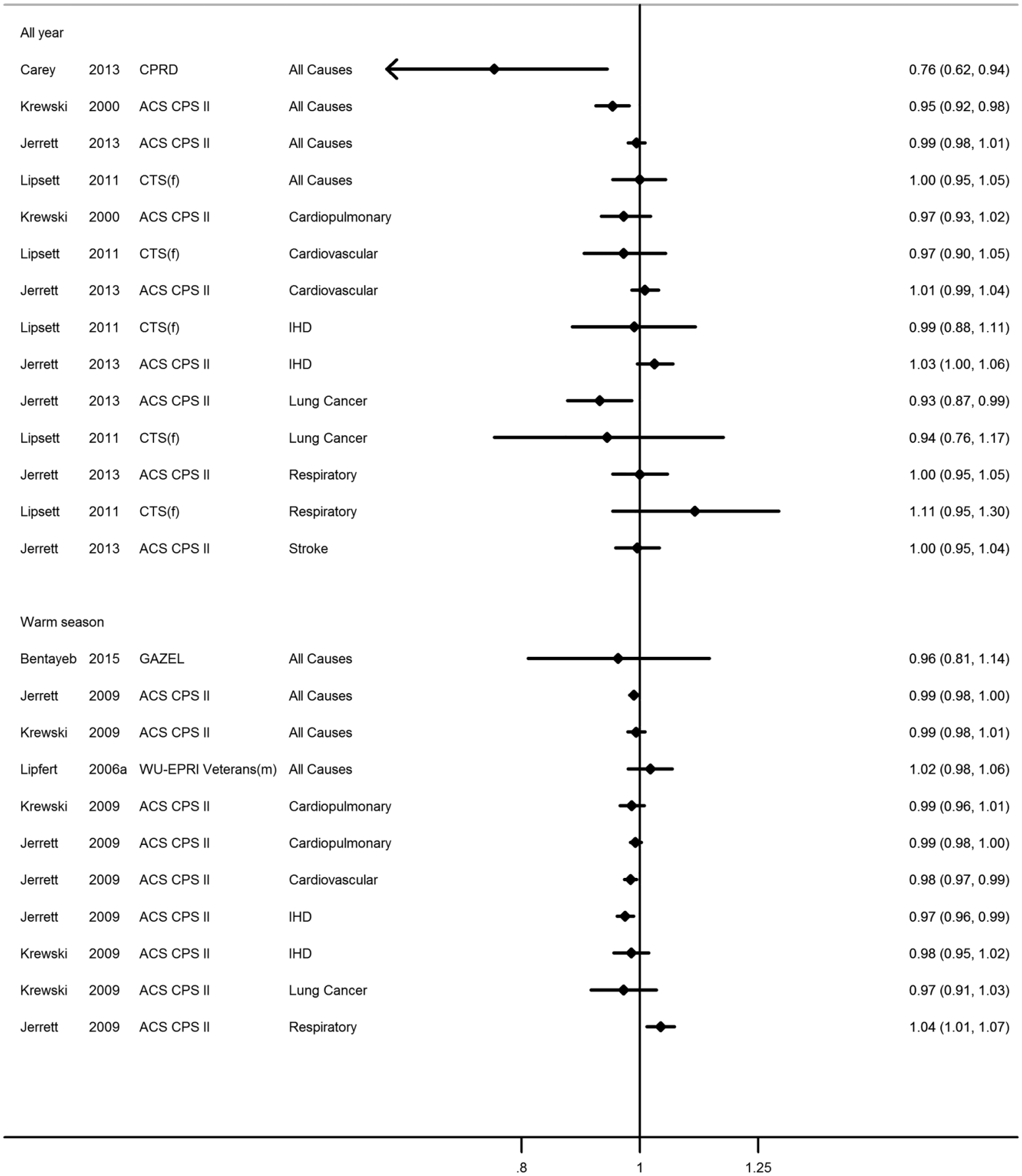

Figure $4 \mathrm{RR}(95 \% \mathrm{Cl})$ of death per $10 \mathrm{ppb}$ increase in long-term ozone exposure, adjusted for long-term exposure to $\mathrm{PM}_{2.5}$. Note: For Krewski 2009, ozone increment assumed to be 10 ppb. ACS CPS II, American Cancer Society Cancer Prevention Study II; CTS, California Teachers Study; IHD, ischaemic heart disease; WU-EPRI, Washington University - Electric Power Research Institute Veterans Cohort; RR, relative risk; $\mathrm{PM}_{2.5}$, mass of particles with a median aerodynamic diameter less than $2.5 \mu \mathrm{m}$.

statistical models employed. However, the relatively small number of independent cohorts limits the scope for effect modification analysis with which to explore the relative impact of these important characteristics.

There is also a need for more details of the methods used to determine and assign exposure estimates and statistical models. Some studies used exposure metrics derived from averages, or percentile values, of daily $1 \mathrm{~h}$ concentrations and these may not be the most appropriate measure of lower (by definition) long-term average exposures to $\mathrm{O}_{3}$. Studies using such metrics may actually be investigating associations with repeat exposures to the 
highest $\mathrm{O}_{3}$ concentrations rather than investigating associations with long-term (ie, cumulative) exposure. However, cohort studies exploit spatial variation in individual exposure estimates and report HRs for an increment in the $\mathrm{O}_{3}$ concentrations. Therefore, if the statistical model assumes a linear concentration response function (and most do), then the exact metric used is less important and estimates can be combined in a meta-analysis. However, the selected $\mathrm{O}_{3}$ metrics (and the concentrations they represent) may be a source of heterogeneity in any meta-analysis if there is, in reality, a non-linear concentration response function. None-the-less, the exact definition of the exposure metric used in each analysis has an important bearing on the utility of study results in health impact assessment exercises where a concentration response function is applied to a change in pollution concentration.

Our review reveals the paucity of population-based cohorts from which to draw substantive conclusions about the health effects associated with the long-term exposure to $\mathrm{O}_{3}$. One cohort comprised participants with pre-existing medical conditions, ${ }^{33}$ and others selected participants based on employment ${ }^{12} 3637$ or specific participant characteristics. ${ }^{30}$ The ACS CPS II cohort utilised friends, neighbours, acquaintances and relatives of volunteers and is therefore unlikely to be representative of the US general population and the Six Cities cohort is restricted to white participants. Only the English cohort based on an administrative database of patients registered with general practitioners (which is almost universal in the UK) is population based. While studies in selected subgroups support hazard assessment, their findings have limited application in quantifying the risk in the general population. The use of large, linked administrative databases ${ }^{9}$ may enable a growth in the number of studies reporting results which are nationally representative. There is also a need for cohort studies outside of the USA in order to provide a broader evidence base across a range of $\mathrm{O}_{3}$ concentrations and where relationships between $\mathrm{O}_{3}$ and co-variables of temperature and other pollutants may be different. This contrasts sharply with the large volume of epidemiological evidence from time-series studies investigating associations from short-term exposure to $\mathrm{O}_{3} .{ }^{1}$ This literature incorporates a wide range of health outcomes/diseases and from many regions of the world, including stratification by season. This evidence from short-term exposure studies worldwide does, however, provide support for the application of results from long-term exposure studies in locations with cohort evidence to regions without such evidence. ${ }^{11}$

A number of publications using the ACS CPS II cohort have assessed associations between $\mathrm{O}_{3}$ concentrations measured during the warmer months of the year and mortality and have reported positive associations with lower confidence limits very close to 1 (figure 3 ). Krewski et $a l^{29}$ reported results for $\mathrm{O}_{3}$ measured both throughout the year and during April to September.
They found stronger associations for cardiopulmonary mortality using measures of $\mathrm{O}_{3}$ during the warmer months compared with all year (incorporating comparable confounder adjustment-ref. 29, table 3; 1.03 (95\% CI 1.02 to 1.04$)$ vs 1.01 (95\% CI 1.00 to 1.03$)$ respectively. Similarly, Lipfert $e t a l^{33}$ reported a positive association between peak exposure $(95 \%$ centile of daily maximum hourly ozone) and mortality but not with the annual mean. However, this pattern of associations was not observed in a similar comparison using the CTS cohort. $^{36}$

The reasons for the modest differences between HRs estimated using warm season and all year concentrations in the ACS CPS II study are not clear. One possibility is that exposure measurement error varies between seasons due to different patterns of human behaviour (eg, time spent outdoors or window opening). ${ }^{42}$ It may suggest a non-linear concentration response function with larger HRs during the higher ozone concentrations experienced during the warmer months compared with the cooler months of the year though we note that $\mathrm{O}_{3}$ in the northern hemisphere can be high earlier in the year. However, the ranges of ozone exposures in the warm and all year periods were not that dissimilar, 11.756.4 vs 10.4-41.1 ppb, respectively, although means (30.2 vs 22.9 ), medians (30.7 vs 22.5 ) and variances (40.9 vs 21.5) differed substantially. ${ }^{29}$ An analysis of summer ozone concentrations using the ACS CPS II $^{26}$ examined the shape of the concentration-response function and did not find evidence that a threshold model specification improved model fit over the linear, non-threshold model. Ozone production during summer episodes is closely related to temperature and solar radiation; hence, the question of whether or not ozone associations observed during the warmer months are independent of the effects of temperature requires investigation. Jerrett $e t a l,{ }^{26}$ in their analyses of summer ozone concentrations in the USA, found no evidence of confounding by temperature but did report a modifying effect of temperature on the ozone HRs.

Concentrations of ozone at a given time and place are determined not just by its photochemical production, but also the rate of chemical loss, the rate of surface deposition, and of long-range atmospheric transport which vary by season and meteorological conditions. Correlations with other pollutants, including $\mathrm{NO}_{2}$ and particles, also vary by season. Therefore, studies of the health effects associated with long-term ozone concentrations should consider, if possible, the numerous complexities involved including (1) seasonal patterns of ozone production/loss; (2) whether relationships are driven by temperature; (3) the shape of the concentration response relationship; and (4) the impact of co-pollutants.

Climate impacts directly or indirectly on many processes that determine the concentrations of ozone at a particular location and time. ${ }^{43}{ }^{44}$ Climate-mediated influences on ozone include those related to emission 
fluxes of ozone precursors, atmospheric chemistry, dispersion and transport, and loss of ozone by dry deposition to vegetation. Climate change may influence future anthropogenic emissions of ozone precursors indirectly through mitigation and adaptation responses, such as reduced energy demand for space heating in winter but greater energy demand for air conditioning in summer. Biogenic emissions of ozone precursors will also be influenced by climate change. For those climatemediated processes included in model simulations to date, modelling studies ${ }^{45}$ indicate that, overall, the net impact of climate change on surface ozone is generally a decrease in remote (low $\mathrm{NO}_{\mathrm{x}}$ ) areas, but an increase in some densely populated (high $\mathrm{NO}_{\mathrm{x}}$ ) areas. ${ }^{46}$ Human exposure to ambient ozone may also be affected by behavioural changes arising from adaptive strategies. ${ }^{47}$ Studies of long-term exposure to ozone may therefore have increasing relevance in the future if concentrations of ozone rise in densely populated urban areas.

Our quantitative review of the literature revealed a paucity of independent, population-based studies regarding the effects of long-term exposure to ozone on mortality. Furthermore, the evidence from outside the USA was very limited. However, there is a suggestion of a modest, adverse association between long-term ozone concentrations measured during the warmer months of the year and cardiopulmonary and respiratory mortality. The need for concentration response functions for burden estimation and evaluation of impacts of climate change will require further large, population-based cohorts utilising comparable ozone metrics.

\author{
Author affiliations \\ ${ }^{1}$ Population Health Research Institute and MRC-PHE Centre for Environment \\ and Health, St George's, University of London, London, UK \\ ${ }^{2}$ Environmental Change Department, Centre for Radiation, Chemical and \\ Environmental Hazards, Public Health England, Oxon, UK \\ ${ }^{3}$ School of Chemistry, University of Edinburgh, Edinburgh, UK \\ ${ }^{4}$ RICARDO-AEA, Harwell IBC, Didcot, Oxfordshire, UK \\ ${ }^{5}$ Environment Department, University of York, York, UK \\ ${ }^{6}$ National Heart \& Lung Institute, Imperial College London and MRC-PHE \\ Centre for Environment \& Health, Imperial College London, London, UK \\ ${ }^{7}$ MRC-PHE Centre for Environment and Health, King's College London, \\ London, UK
}

Contributors RWA, BKB, SD contributed to the conception and design of the study. RWA, BKB contributed to the analysis of data. All authors contributed to the interpretation of data and drafting of the manuscript.

Funding This research received no specific grant from any funding agency in the public, commercial or not-for-profit sectors. The contribution of HW to the research was supported by the National Institute for Health Research (NIHR) Biomedical Research Centre at Guy's and St Thomas' NHS Foundation Trust and King's College London and by the NIHR Health Protection Research Unit on the Health Impacts of Environmental Hazards at King's College London in partnership with Public Health England (PHE). The views expressed are those of the author and not necessarily those of the NHS, the NIHR, the Department of Health or Public Health England.

Competing interests BKB has shares in Royal Dutch Shell and in Scottish and Southern Energy.

Provenance and peer review Not commissioned; externally peer reviewed.

Data sharing statement No additional data are available.
Open Access This is an Open Access article distributed in accordance with the Creative Commons Attribution Non Commercial (CC BY-NC 4.0) license, which permits others to distribute, remix, adapt, build upon this work noncommercially, and license their derivative works on different terms, provided the original work is properly cited and the use is non-commercial. See: http:// creativecommons.org/licenses/by-nc/4.0/

\section{REFERENCES}

1. World Health Organisation. Review of evidence on health aspects of air pollution-REVIHAAP project: final technical report. 2013. http:// www.euro.who.int/en/health-topics/environment-and-health/airquality/publications/2013/review-of-evidence-on-health-aspects-ofair-pollution-revihaap-project-final-technical-report

2. The Royal Society. Ground-level ozone in the 21st century: future trends, impacts and policy implications. 2008; Report 15/08. https:// royalsociety.org/topics-policy/publications/2008/ground-level-ozone/

3. Air Quality Expert Group. Ozone in the United Kingdom. 2009. http:// www.defra.gov.uk/environment/airquality/publications/ozone/pdf/ aqeg-ozone-report.pd

4. Heal MR, Heaviside C, Doherty RM, et al. Health burdens of surface ozone in the UK for a range of future scenarios. Environ Int 2013;61:36-44.

5. Health Effects of Climate Change in the UK 2012. Current evidence, recommendations and research gaps. Health Protection Agency, UK. 2012. https://www.gov.uk/government/uploads/system/uploads/ attachment_data/file/371103/Health_Effects_of_Climate_Change_in the UK 2012 V13 with cover accessible.pdf

6. Environmental Protection Agency. Integrated science assessment for ozone and related photochemical oxidants. 2013; Report No.: EPA 600/R-10/076F.

7. World Health Organisation. WHO Air quality guidelines for particulate matter, ozone, nitrogen dioxide and sulphur dioxide. 2006. http:// apps.who.int/iris/bitstream/10665/69477/1/WHO_SDE_PHE_OEH_ 06.02_eng.pdf

8. Environmental Protection Agency. Air quality criteria for ozone and related photochemical oxidants (2006 final). 2006; Report No.: EPA/ 600/R-05/004AF.

9. Carey IM, Atkinson RW, Kent AJ, et al. Mortality associations with long-term exposure to outdoor air pollution in a national English cohort. Am J Respir Crit Care Med 2013;187:1226-33.

10. Jerrett M, Burnett RT, Beckerman BS, et al. Spatial analysis of air pollution and mortality in California. Am J Respir Crit Care Med 2013;188:593-9.

11. Lim SS, Vos T, Flaxman AD, et al. A comparative risk assessment of burden of disease and injury attributable to 67 risk factors and risk factor clusters in 21 regions, 1990-2010: a systematic analysis for the Global Burden of Disease Study 2010. Lancet 2012;380:2224-60.

12. Tseng $\mathrm{E}, \mathrm{Ho} \mathrm{WC}$, Lin $\mathrm{MH}$, et al. Chronic exposure to particulate matter and risk of cardiovascular mortality: cohort study from Taiwan. BMC Public Health 2015;15:936-2272.

13. Krewski D, Burnett RT, Goldberg MS, et al. Overview of the reanalysis of the Harvard Six Cities Study and American Cancer Society Study of Particulate Air Pollution and Mortality. J Toxicol Environ Health A 2003;66:1507-51.

14. Dockery DW, Pope CA III, Xu X, et al. An association between air pollution and mortality in six US cities. $N$ Engl $J$ Med 1993;329:1753-9.

15. Health Effects Institute. Reanalysis of the Harvard Six Cities Study and the American Cancer Society Study of Particulate Air Pollution and Mortality: A Special Report of the Institute's Particle Epidemiology Reanalysis Project. Cambridge, MA: Health Effects Institute, 2000.

16. Pope CA III, Burnett RT, Thun MJ, et al. Lung cancer, cardiopulmonary mortality, and long-term exposure to fine particulate air pollution. JAMA 2002;287:1132-41.

17. Abbey DE, Mills PK, Petersen FF, et al. Long-term ambient concentrations of total suspended particulates and oxidants as related to incidence of chronic disease in California Seventh-Day Adventists. Environ Health Perspect 1991;94:43-50.

18. Mills PK, Abbey D, Beeson WL, et al. Ambient air pollution and cancer in California Seventh-day Adventists. Arch Environ Health 1991;46:271-80.

19. Goss $\mathrm{CH}$, Newsom SA, Schildcrout JS, et al. Effect of ambient air pollution on pulmonary exacerbations and lung function in cystic fibrosis. Am J Respir Crit Care Med 2004;169:816-21.

20. Spencer-Hwang R, Knutsen SF, Soret S, et al. Ambient air pollutants and risk of fatal coronary heart disease among kidney transplant recipients. Am J Kidney Dis 2011;58:608-16. 
21. Zanobetti A, Schwartz J. Ozone and survival in four cohorts with potentially predisposing diseases. Am J Respir Crit Care Med 2011;184:836-41.

22. Zanobetti A, O'Neill MS, Gronlund CJ, et al. Summer temperature variability and long-term survival among elderly people with chronic disease. Proc Natl Acad Sci USA 2012;109:6608-13.

23. Bhinder $\mathrm{S}$, Chen $\mathrm{H}$, Sato $\mathrm{M}$, et al. Air pollution and the development of posttransplant chronic lung allograft dysfunction. Am J Transplant 2014;14:2749-57. http://onlinelibrary.wiley.com/journal/10.1111/ (ISSN)1600-6143.

24. Lipfert FW, Perry HM Jr, Miller JP, et al. The Washington University-EPRI Veterans' Cohort Mortality Study: preliminary results. Inhal Toxicol 2000;12(Suppl 4):41-73.

25. Krewski D, Burnett RT, Goldberg M, et al. Reanalysis of the Harvard Six Cities Study, part II: sensitivity analysis. Inhal Toxicol 2005; 17:343-53

26. Jerrett M, Burnett RT, Pope CA III, et al. Long-term ozone exposure and mortality. N Engl J Med 2009;360:1085-95.

27. McDonnell WF, Nishino-Ishikawa N, Petersen FF, et al. Relationships of mortality with the fine and coarse fractions of long-term ambient PM10 concentrations in nonsmokers. J Expos Anal Environ Epidemiol 2000;10:427-36.

28. Jerrett M, Burnett RT, Ma R, et al. Spatial analysis of air pollution and mortality in Los Angeles. Epidemiology 2005;16:727-36.

29. Krewski D, Jerrett M, Burnett RT, et al. Extended Follow-Up and Spatial Analysis of the American Cancer Society Study Linking Particulate Air Pollution and Mortality. HEI Research Report 140. Boston, MA: Health Effects Institute, 2009.

30. Abbey DE, Nishino N, McDonnell WF, et al. Long-term inhalable particles and other air pollutants related to mortality in nonsmokers. Am J Respir Crit Care Med 1999;159:373-82.

31. Lipfert FW, Perry HM Jr, Miller JP, et al. Air pollution, blood pressure, and their long-term associations with mortality. Inhal Toxicol 2003;15:493-512.

32. Chen LH, Knutsen SF, Shavlik D, et al. The association between fatal coronary heart disease and ambient particulate air pollution: Are females at greater risk? Environ Health Perspect 2005;113:1723-9.

33. Lipfert FW, Baty JD, Miller JP, et al. PM2.5 constituents and related air quality variables as predictors of survival in a cohort of US military veterans. Inhal Toxicol 2006;18:645-57.
34. Lipfert FW, Wyzga RE, Baty JD, et al. Traffic density as a surrogate measure of environmental exposures in studies of air pollution health effects: long-term mortality in a cohort of US veterans. Atmospheric Environ 2006;40:154-69.

35. Smith KR, Jerrett M, Anderson HR, et al. Public health benefits of strategies to reduce greenhouse-gas emissions: health implications of short-lived greenhouse pollutants. Lancet 2009;374:2091-103.

36. Lipsett MJ, Ostro BD, Reynolds P, et al. Long-term exposure to air pollution and cardiorespiratory disease in the California teachers study cohort. Am J Respir Crit Care Med 2011;184:828-35.

37. Bentayeb M, Wagner V, Stempfelet M, et al. Association between long-term exposure to air pollution and mortality in France: a 25-year follow-up study. Environ Int 2015;85:5-14

38. Moher D, Liberati A, Tetzlaff J, et al. Preferred Reporting Items for Systematic Reviews and Meta-Analyses: The PRISMA Statement. BMJ 2009;339:b2535.

39. Jerrett M, Finkelstein MM, Brook JR, et al. A cohort study of traffic-related air pollution and mortality in Toronto, Ontario, Canada. Environ Health Perspect 2009;117:772-7.

40. Prueitt RL, Lynch HN, Zu K, et al. Weight-of-evidence evaluation of long-term ozone exposure and cardiovascular effects. Crit Rev Toxicol 2014;44:791-822.

41. The Mortality Effects of Long-Term Exposure to Particulate Air Pollution in the United Kingdom. 2009. https://www.gov.uk/ government/uploads/system/uploads/attachment_data/file/304641/ COMEAP mortality effects of long term exposure.pdf

42. Weschler $\mathrm{CJ}$. Ozone in indoor environments: concentration and chemistry. Indoor Air 2000;10:269-88.

43. Jacob DJ, Winner DA. Effect of climate change on air quality. Atmospheric Environ 2009;43:51-63.

44. Fiore AM, Naik V, Spracklen DV, et al. Global air quality and climate. Chem Soc Rev 2012;41:6663-83.

45. Athanassiadou M, Baker J, Carruthers D, et al. An assessment of the impact of climate change on air quality at two UK sites. Atmospheric Environ 2010;44:1877-86.

46. Wu S, Mickley LJ, Jacob D, et al. Effects of 2000-2050 changes in climate and emissions on global tropospheric ozone and the policyrelevant background surface ozone in the United States. J Geophys Res 113, D18312, 2008. doi:10.1029/2007JD009639

47. Smit B, Wandel J. Adaptation, adaptive capacity and vulnerability. Global Environ Change 2006;16:282-92. 